\title{
Some Distinctive Features of Narrative Environments
}

\author{
Tricia Austin
}

\author{
Central Saint Martins \\ University of the Arts London \\ United Kingdom
}

\begin{abstract}
This paper explores key characteristics of spatial narratives, which are called narrative environments here. Narrative environments can take the form of exhibitions, brand experiences and certain city quarters where stories are deliberately being told in, and through, the space. It is argued that narrative environments can be conceived as being located on a spectrum of narrative practice between media-based narratives and personal life narratives. While watching a screen or reading a book, you are, although often deeply emotionally immersed in a story, always physically 'outside' the story. By contrast, you can walk right into a narrative environment, becoming emotionally, intellectually and bodily surrounded by, and implicated in, the narrative. An experience in a narrative environment is, nonetheless, different from everyday experience, where the world, although designed, is not deliberately constituted by others intentionally to imbed and communicate specific stories. The paper proposes a theoretical framework for space as a narrative medium and offers a critical analysis of two case studies of exhibitions, one in a museum and one in the public realm, to support the positioning of narrative environments in the centre of the spectrum of narrative practice.
\end{abstract}

Keywords: media-based narratives, narrative environments, life narrative 


\section{Introduction}

Theory about spatial narrative has developed in the last 25 years with insightful contributions from Potteiger and Jamie (1998), who write about landscape and narrative, Kossmann, Mulder and Oudsten (2012), who discuss exhibition narratives, Psarra (2009), who analyses architectural, and urban design narratives, and Ryan (2016) who has pioneered transmedial narrative theory. My colleagues and I who founded MA Narrative Environments at Central Saint Martins, University of the Arts London, have looked to narratology, psychology and spatial theory to evolve some underpinning principles for the analysis and the design of narrative environments. This investigation has revealed, firstly, two main traditions in narrative theory, one deriving from literary theory and the other from psychology. This research has, secondly, enabled us to align and relate to four areas of theory: the literary narrative theories of Greimas $(1983,1987)$; theories of life narrative proposed by psychologist Bruner (1991); theories of embodied perception developed by Merleau-Ponty (2005); and theories of the construction of space advanced by Lefebvre (1991).

Literary narratives differ from cinematic narratives and theatre narratives. For example, while text in books can directly communicate a character's thoughts, inner thoughts need to be acted out or translated into dialogue in cinema and theatre. Cinema can shift the point of view by cutting from close-ups to panoramas, for example, while theatre usually is constructed for a fixed audience viewpoint. However, literature, cinema and theatre do share key characteristics, and the one that is relevant here is that, conventionally, the audience for all three forms of narrative is stationary. When reading a book or visiting the cinema or traditional theatre, in other words, while we turn the pages, while the screen flickers or the actors move, our bodies are relatively immobile. By contrast, in narrative environments, the visitors move through the narrative space and consequently play a more physically active and indeed rather different role in the unfolding of the narrative, as is discussed below. An exhibition visitor, for example, is more engaged through full-body, sensory stimuli and the author of the exhibition loses the power to order strictly the sequence of events. Visitors will move as they wish within accepted cultural norms, as in everyday life.

How do narrative environments differ from life narratives? Psychologist Bruner (1991), argues from a constructivist position, that autobiographies or the stories we use to construct and play out our identities are developed from the interplay among self, others and the world. We consciously and unconsciously incorporate 
events into our personal narratives and consequently rationalise our life experiences as an unfolding story. In other words, everyone is constructing a narrative of self at all times. However, Perec (2008) suggests that because everyday life comprises the banal, the quotidian, the obvious, the common, the ordinary, the habitual, we take it for granted. It can go unnoticed and overlooked. It is argued here that when we visit exhibitions, brand experiences or new city quarters where a story or stories are deliberately being communicated, we expect the experience to be different from daily life. Consequently, we are primed to take particular notice of our surroundings and explore meanings more attentively in narrative environments. Indeed, it is argued here that the contextual frame, which we recognise from our everyday world, signals the meaning or importance of space and affects our readiness or reluctance to consciously engage in a new narrative. Take, for example, the experience of standing in front of the entrance to a large museum. While one person might be drawn in, another might be discouraged from entering by the symbolism of high culture. It is suggested below that, irrespective of whether the spatial context is a museum building or a public square, the contextual frame asserts particular values which shape the reception and the telling of stories.

Like media narratives, narrative environments are intentionality designed and built to communicate stories to specific audiences or prompt storytelling among visitors. Although audiences move through narrative environments using the same bodily movements as they use in the everyday, design teams dramatise transitions from one space to another by using scale, form, light and materiality to prompt bodily reactions, structure the unfolding narrative and implicitly communicate aspects of the story. Designers work on sensory principles that combine space and time. Examples include the delight that is triggered in some people by being squeezed through quite small spaces to emerge in large spaces; how wandering is prompted by alternating pools of light and dark which can produce a relationship between proximity and distance increasing anticipation of what is yet to come; how physical screens can artfully conceal and then reveal, producing a certain gratification; and how moments of concentration can be created in front of staged objects.

To explore further the distinctive characteristics of narrative environments and their position on a spectrum of narrative practice, this article provides a critical analysis of two exhibitions on topics from popular culture: music and design. The first case study, The Pink Floyd exhibition Their Mortal Remains at the Victoria and Albert Museum, (V\&A) London in 2017, 13 May-15 October, was more like media narrative; it was linear and framed by a grand 
museum. The second, the installation Gateways by Adam Nathanial Furnam at Kings Cross in September 2017, 21-24 September, part of designjunction, was less linear, set in the public/private urban realm and therefore more akin to everyday experience. The analysis was based on observations made on visits to the exhibitions, interviews and the application of the theoretical framework explained below.

\section{Theoretical Foundations}

To grasp the drive to tell stories, MA Narrative Environments (MANE), firstly, turns to the ancient Greek notion of agon, which has been described as movement through competition and struggle by Hawhee (2002). We understand agon to be in play in real life and in story. It emerges in real life from the social, political, environmental and psychological frictions in which we are involved as participants. In imagining how these struggles may play out and be resolved, we create stories. On MANE, we align this notion of agon to that of "dramatic conflict" (McKee, 1999) as the persistent tension or the driving force that defines the dynamic, and consequently the content, of stories. These stories may be ways of explaining the past or imagining the future, irrespective of whether they conflict is fully resolved or not.

Narrative environments are, secondly, developed by multidisciplinary teams of content developers and designers. The designs articulate rhythms and contrasts in spatial arrangements; objects; images; text; qualities of materiality, light, colour, sound; digital layers of information; and affordances for the behaviour of people in the space.

Having adopted a theory of persistent tension that drives stories, we turn to A.J. Greimas (1983) for further elaboration of the dynamics of story. In his theory of narrative structure, Greimas conceived of three pairs of contraries: sender vs. receiver; subject vs. object; and helper vs. opponent. He argued that these contraries generate three types of relations, operating as intersecting narrative axes: knowledge, constituted by communication between sender and receiver; desire, which is felt by the subject for the object; and power, realised through the agonistic struggle experienced by the subject to acquire or achieve the object of desire, a goal facilitated by the helper and hindered by the opponent.

Greimas further explains his theory of the dynamics of narrative structure through analysing the legend The Search for the Holy Grail. The sender is an apparition who commands the receivers, King Arthur and his knights, to search for the Holy Grail. The 
apparition opens up the axis of knowledge by telling the knights about the existence of the Holy Grail, of which they had previously been ignorant. The knights then become the active subjects, the protagonists who seek the object of the Holy Grail. In that moment of coming to know, the axis of desire is activated. The helpers assist the knights to find the Holy Grail and take it to the Middle East, while opponents put obstacles in the knights' way as they pursue their goal, thereby activating the axis of power relations by means of which the struggle is realised in practice. In Greimas' theorisation, neither helpers nor opponents need to be human characters. For example, the opponents may take the form of a mountain range, a desert or the Saracens.

Greimas' scheme is valuable as it captures significant dynamics of knowledge, desire and power at play in narrative and it is suggested here that we can use these story dynamics to make more engaging narrative environments. This three-pair structure can also be used to analyse narrative environments, as in the case studies below. This paper does not claim that all stories can be reduced to these three axes but suggests this scheme enables us to consider story dynamics that capture the emotion and the imaginative aspects of narratives. This is a dynamic interpretation of Greimas' structural approach to narrative.

Greimas (1987), in his linguistic research, also proposed a diagram to characterise meaning production, called the semiotic square. The semiotic square can be applied to different situations and Parsons (2017), a lecturer on MA Narrative Environments, has interpreted the semiotic square in relation to Jacques Lacan's Schema $L$ (Wegner, 2010), which theorises the human subject as divided, and to the work of Bruno Latour and others who theorise the human subject as both actor and as element of network (Latour, 2005; 2014).

Parsons' purpose is to develop a tool that is capable of analysing literary narratives, narrative environments and narratives of self and understanding their potential inter-relationships. Starting from the pair of contraries, 'I' and 'me', a Greimasian contrast with a Lacanian emphasis, Parsons applies the Greimasian principle of the semiotic square to generate the further terms 'not-I' and 'not-me'. From there, Parsons envisages the emergence of four worlds 'my world', 'our world', 'your world' and 'their world', as a complex Latourian actornetwork, with its specific tensions and conflicts. This approach is useful because it allows us to conceive of the spatialisation and materiality of thresholds, territory and the identification with, or alienation from content and place, as well as the inter-relationships, through the ' $\mathrm{I}$ ' and the 'me' of narrativization and spatialisation. Parsons argues the worlds are not undifferentiated nor singular. 
We sense, from the environmental cues and affordances, when we are leaving our own world venturing into someone else's world, a shared world or an alien world. We need to feel safe, in our world, but we also desire new knowledge about the power relations which structure our world and its relations to other worlds. The notion here is that the world of any specific narrative environment will be experienced as 'my', 'our,' 'your', 'their' world, depending on how you are addressed and positioned by the narrative environment. It is never experienced neutrally. This analysis of different worlds, when applied to literary stories, spatial narratives and everyday life situations, can reveal the gulfs and possible links and alliances among individuals, groups, organisations and institutions. This approach is particularly useful for analysing and developing narrative spaces, as will be demonstrated in the case study analyses below, because the embodied audience physically enters spatial narratives, whether in the context of a museum or in the public realm. Spatial narratives invite and endeavour to order these different embodied selves by drawing them together, for example, as a community of place or community of interest, using physical and communication techniques that can be critical of normative values, to differing degrees.

In order to explore spatial narrative, we also need relevant theories of space and materiality. Here we can turn to the lineage of phenomenology which looks at embodied perception. MerleauPonty (2005) argues that humans develop a body schema that comprises not only our physical body but also its relationship to the surrounding world. In other words, we carry with us a sense of depth, dimensionality, flow, movement, form, colour, tactility, texture and lustre. Merleau-Ponty also asserts that we make meaning firstly from what we experience in the immediate world around us. This suggests the cues to the story can be sensory and experiential relying on, for example, implicit cues of scale, proximity and distance, sightlines, as well explicit cues such as posters, printed words, digital media. On MANE, we follow Merleau-Ponty in maintaining the body functions in unity with the mind and that our body schema is largely unconscious as long as the flow of interaction between our body and the environment is familiar and uninterrupted. So although, as visitors within narrative environments, we need a familiar spatial frame to situate ourselves, we also need a certain degree of disruption to engage us. Rhythms and zones control and disrupt the space through their distribution, density and alignment. Sightlines to the next rooms or sections help anticipate both our movement forward and the resolution of the story. Also as visitors, we mentally, emotionally and bodily weave in and out of 'my world,' 'your world', 'our world' and 'their world'. 
At this point, we turn to Lefebvre (1991) who argues that there is no strict division between physical spaces and mental spaces but that all spaces are produced, lived and understood through relationships of power. Lefebvre maintains that all space is subject to some kind of struggle. As such, he points to the potential dramatic conflict in space while defining three kinds of space: first, conceived space, that of planners and developers or, in other words, powerful authorities who decide where streets and houses are placed; second, perceived space, read by inhabitants who have learned to interpret the symbolic meanings of the built and/or natural environment; and, third, space produced by spatial practices, in other words, the way we each customise or contest spatial conventions and regulations finding our own routes, modifying our own homes, sometimes transgressing accepted codes of conduct. Using Lefebvre, we are prompted to ask about the conceived space of the museum and the public square asking who made the space like this, for whose benefit and to what ends? Who recognises the symbolic meaning and in what different ways? How do people find their own routes and meanings in the museum or the public realm and how do people transgress the conventions of these spaces?

In the next sections these narrative and spatial theories are used as an analytical framework which will aim, firstly, to reveal the importance of expressing dramatic conflicts and story dynamics in narrative environments; secondly, to explore the distinctive role of the visitor in narrative environments as they negotiate 'my', 'our', 'your', 'their' worlds within specific cultural frames; and, thirdly, to help identify some the ways in which narrative environments embody and express stories through physical and sensory form.

\section{Case Study One: Their Mortal Remains at the V\&A}

Their Mortal Remains was one of a series of hugely successful blockbuster exhibitions at the V\&A which included those on David Bowie and Alexander McQueen. The V\&A was established as a Museum of Manufacturers in 1852. Its mission is to be recognised as the world's leading museum of art, design and performance and to promote the relevance of their collections to the UK creative and knowledge economy. Housed within an imposing Victorian building, it focuses on design and its application in the world at large and, as such, exhibitions of popular culture are fitting, even though the physical frame, collection and mission of the museum position the institution as a discerning centre of high culture.

Their Mortal Remains was conceived and designed by Stufish Entertainment Architects, founded by the late Mark Fisher. The 
studio is renowned for combining architecture, theatre and live music events and it worked on the staging of the Pink Floyd's Wall Tour in 1980 and the Division Bell Tour in 1994. The exhibition showed the development of the Pink Floyd and their work until the present day. It was staged in the V\&A's temporary exhibition space which is linear and therefore lends itself to chronological accounts. The space is a $U$ shape so visitors encounter a distinctive halfway mark as they step through a lobby and turn almost 360 degrees into the second space. The first half of the exhibition was divided into several distinct spaces. At its threshold, the audience entered the exhibition through a psychedelic bus structure, evoking youth travel in the 1960s and symbolising the journey upon which the visitor is engaging.

Figure 1 The psychedelic bus entry to Their Mortal Remains, Victoria \& Albert Museum, 2017

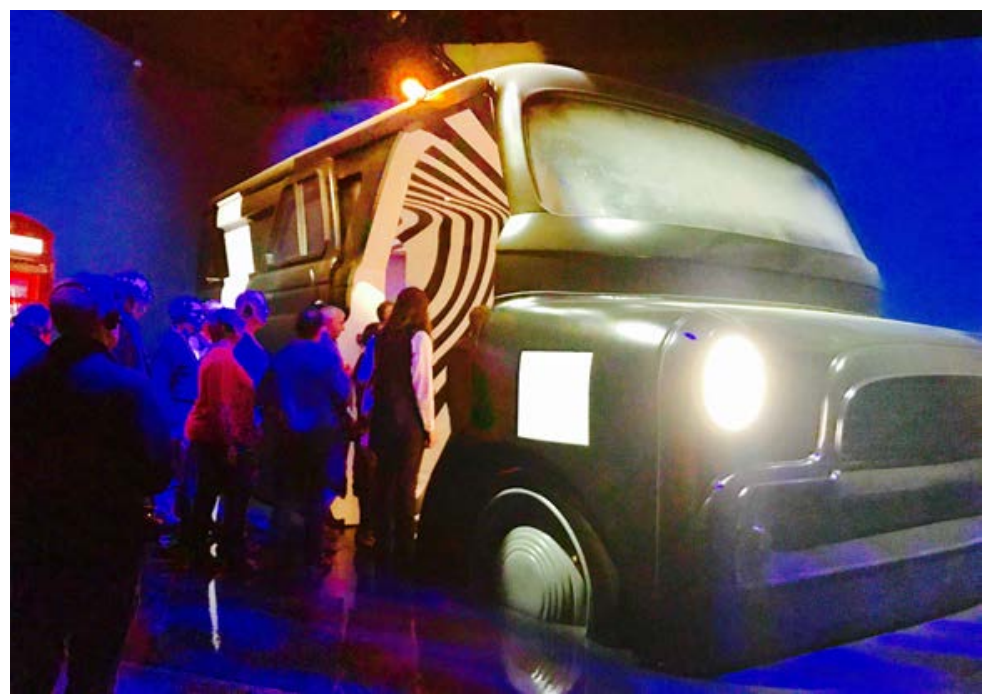

Figure 2 Inside the psychedelic bus

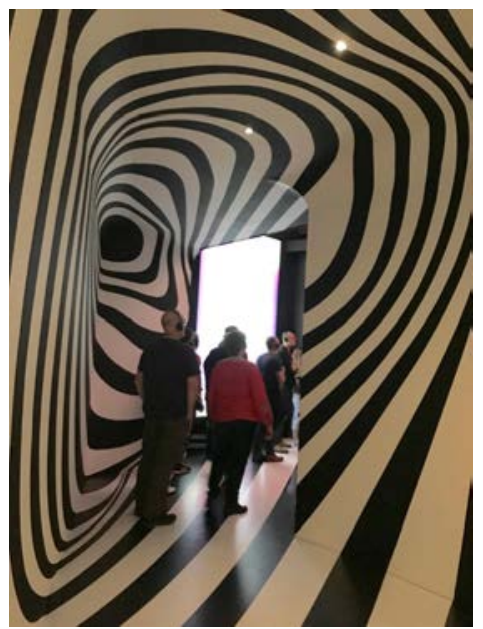


This was followed by several small spaces: the immersive psychedelia of the UFO nightclub; the Syd Barrett story; the collaboration and consolidation of the move to more instrumental music; the release and impact of Dark Side of the Moon; the technology the band used to experiment with sound; and the graphics and stage sets the band developed.

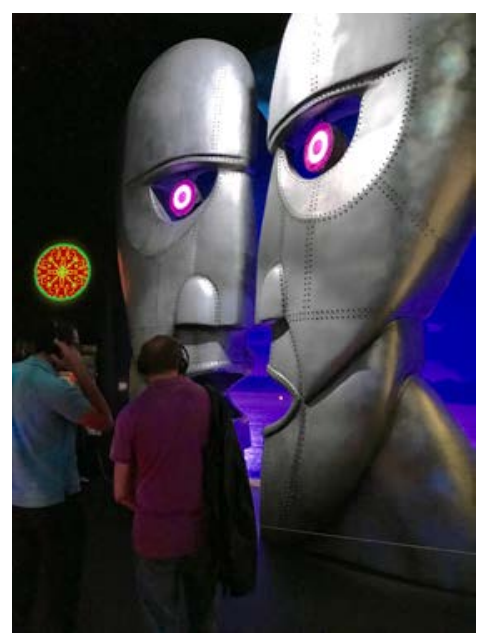

Figure 3

Imagery and staging from the Pink Floyd performances

The second half of the exhibition was highly theatrical. A huge space housed a five-metre-tall simulation of Battersea power station, enormous replicas of floating inflatables referencing the band's album cover, followed by scenographic settings of walls with missing brick-work referencing the band's 1979 rock opera, The Wall. The exhibition culminated in a large immersive media wrap-around room where visitors could sit and be surrounded by projections and swathed in music.

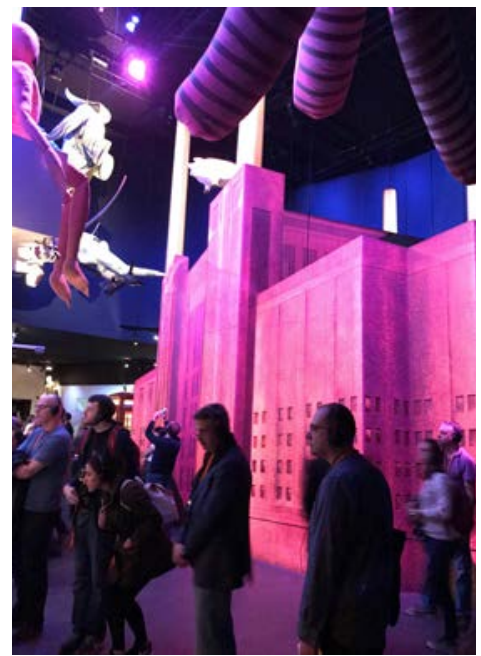

Figure 4

A five-meter high simulations of Battersea power station 
Figure 5

The Wall exhibit

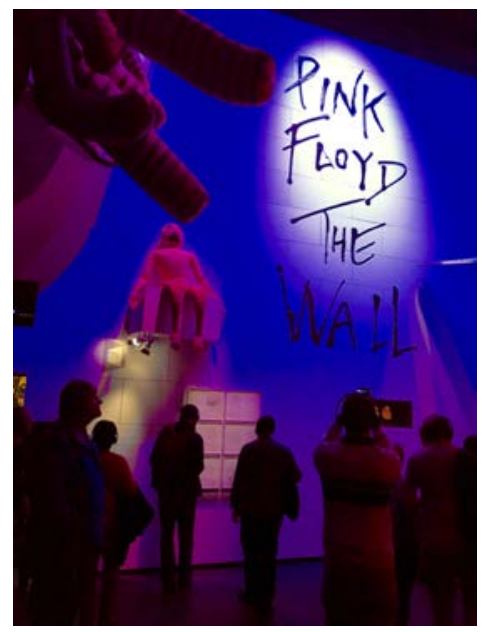

Figure 6 A scenographic staging of missing brickwork

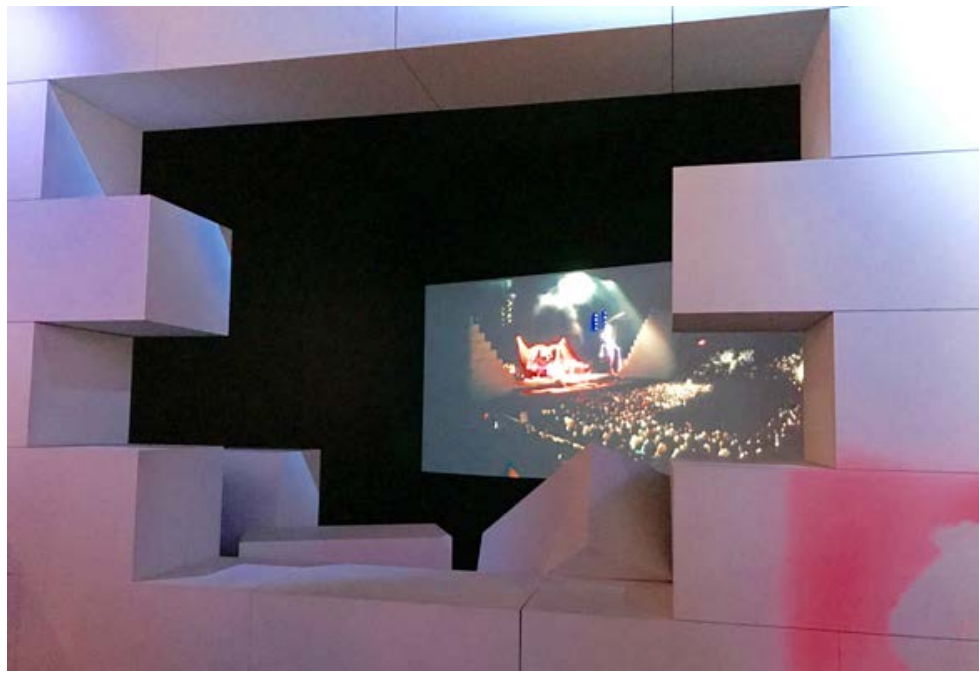

Figure 7 The large immersive media wrap-around experience

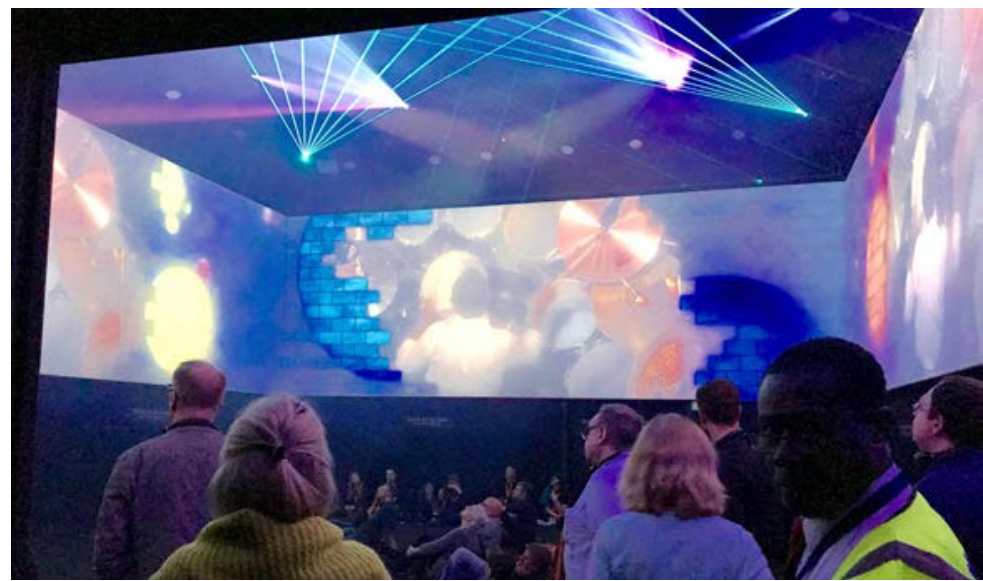


Throughout the exhibition, there were video projections, video screens with talking heads, objects and music graphics, photographs and graphic information panels and labels. Each visitor was given headphones which played Pink Floyd music. The music faded into the sound of talking from the screens as you approached them. Overall, the exhibition moved from the intimacy of the UFO club to the wide-open space of stadium, increasing in scale as you moved along, mirroring the scale of the band's performances and fame.

The dramatic conflict of the story was the Pink Floyd's struggle with the music industry to become recognised, not for being famous as mainstream pop stars but rather for being respected as independent and continuously innovative musicians. However, the exhibition does not show the machinations of the music industry or the context of mass culture but rather presents a series of successes, reinforcing an already circulating mass media and public relations story of the Pink Floyd as superstars. In consequence, the story itself lacks some drama and, for example, young musicians could not learn a great deal about how the industry works to package musicians and performers from the exhibition.

If we take Greimas' narrative model to examine the axes of knowledge, desire and power, we see the knowledge axis manifests through the band's technical accomplishment in sound, light effects and graphics. The band triumph through their determination and skill, reaffirming the overarching brand narrative. The desire axis manifests as a drive to be renowned for their musicianship and creativity, and not simply for the money they earned or their mass media celebrity. However, the aspirations of the Pink Floyd to create the high culture and not produce mass culture were not discussed explicitly in the exhibition which reduced the exhibition's critical dimension. The power axis in Greimas' model manifests in the relationship between the music corporations and music bands, the outcomes of which determine their career paths. Again, these were not discussed or represented in any great detail. All-in-all, the bodily engagement of the visitor is that of a casual stroll, rather than an engagement, along with the band, in an arduous struggle for recognition.

The exhibition itself at the V\&A, acting as a centre for high culture, confirms that the Pink Floyd has achieved this goal while also demonstrating the standing of the $V \& A$ as a frame that validates claimants', in this case, the Pink Floyd, cultural credentials. So, ironically, although the $V \& A$ appears to be bringing popular culture into a place associated with high culture thereby making it more democratic, the power of the V\&A's reputation is so great that it actually shifts the Pink Floyd into the realm of high culture, as the band itself 
would wish or, at least, as some of its band members would wish, as the band itself is famously fractious, another issue which the exhibition skirted over under the corporate brand. It is argued here that famous national museums produce and sustain the framing spatial narrative of high culture for particular countries, bestowed by that country's government and embodied in the grand and imposing architectures and operational practices of the museum institution.

Moving from an analysis of the content of the exhibition to an analysis of the spatial narrative from the visitor's perspective, we apply Greimas' pairs of contraries: the subject and object, the sender and receiver, the helper and opponent. From a content perspective, the band members were couched as subjects whose acts you followed through their hand-written letters, filmed interviews, music, films and pictures of performances. However, from a visitor perspective, you, the visitor, are the subject seeking the object, in other words, what the Pink Floyd means. A crucial point is revealed here. In narrative environments, there is a shift in the role of the visitors. You, the visitor, are not only the recipient of the messages you also become the subject seeking the object, in other words, in this case, you literally set out on a path to find out what the Pink Floyd means.

The headphones at the exhibition were helpers providing music to immerse you in narrative and ambient space but they also stopped you and controlled your journey timing by broadcasting the spoken words from film and video as you came close to the screens. The physical divisions of the space acted as physical opponents preventing you from seeing the next section, acting as concealing, revealing and pacing devices. Other helpers and opponents could be conceived as other visitors who model acceptable visitor behaviour and validate the exhibition just by being there or indeed become obstacles as they block your view or interrupt your thoughts or your passage.

From the perspective of Parsons' analysis of different worlds, the audience stayed in their own world partly because they were sealed inside their headphones, except perhaps at the end when the people sat together on the floor in the wrap-around media room where some people may have felt a sense of 'us' literally as an audience. From the perspective of embodied experience, the rhythm and flow of the space were articulated through the gradual increase in scale corresponding to the success of the band.

The analysis above shows how the dramatic conflict underlies the narrativity and transformational capacity of both the story and the narrative environment and that omitting the opponents, i.e. the obstacles in the way of the band's being recognised for whom they 
wished to be, weakens the narrative and reduces the story to a slick brand narrative. The discussion establishes the exhibition visitor as a key figure in the narrative environment and the potential for embodied and sensory means, sound, image, film, objects, space and other visitors, to act in unfolding the story. It suggests that the visitor, as the subject in Greimas's scheme, should undergo some kind of struggle for the narrative to be transformative. It also flags up that the physical and cultural contextual frame of the museum can serve to perpetuate power relations instead of challenging and prompting critique to educate and inform.

\section{Case Study Two: designjunction, Granary Square}

designjunction was an exhibition at King's Cross, London in September 2017. Part of the annual London Design Festival, designjunction, is an explicitly commercial showcase for large brands and smaller design labels producing interior and product design. It is an exhibition about the design industry for designers, specifiers and buyers but, in 2017, it opened itself to passers-by in Granary Square. It attracted over 28,000 visitors over four days so it was highly successful in terms of footfall.

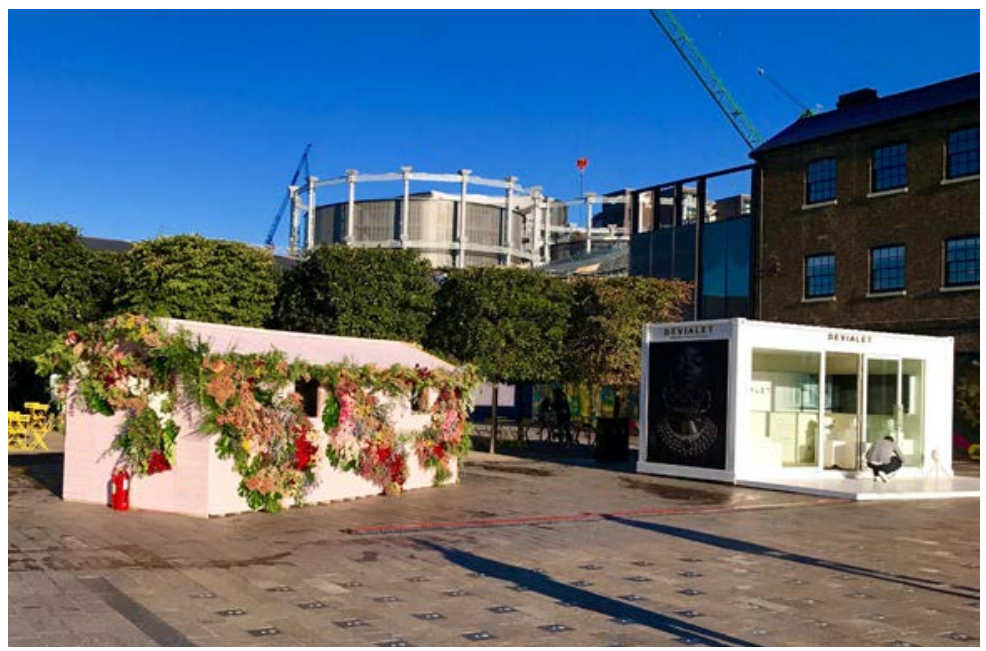

Figure 8 designjunction installations on Granary Square, Kings Cross, London, September 2017

Despite being an explicitly commercial show, designjunction says in its publicity that it wanted to be more than a trade show, it wanted to be an 'immersive' experience, so it chose to locate the display in the new urban development area at King's Cross. Since 2010, Argent, the urban developers, have transformed the 67-acre site, which was formerly a railway and waterways transport hub with a seedy reputation. It is now home to Central Saint Martins (CSM), fashionable and quite expensive eateries and the Museum 
of Illustration. The local council has moved into a new building and Google is constructing its UK headquarters there. As part of its strategy for King's Cross to become an up-market visitor destination, Argent curates events and exhibitions in its 'public' space, i.e. an apparently public space which is in fact carefully managed, although accessible, private property. designjunction chose to cluster its installations and popups into four hubs around CSM in the Granary building on Granary Square. The Granary Square exhibition was the most conspicuous and was not ticketed.

Applying Greimas' model to the designjunction, it is suggested the story dynamics work as follows. The brands have sent designers, as subjects, in pursuit of knowledge of how to improve on existing design and become both celebrities and commercially successful. The object of desire is the knowledge and creativity which opens the door to the world of design celebrity and its material rewards.

The designer has pursued new design embracing technical innovation and defying aesthetic convention. The designer has competed with others to achieve his/her status. $\mathrm{He} /$ she is helped by contacts in the industry and exposure such as the designjunction exhibition and the resulting flow of Instagram images and other social media. This is a heroic tale. This story reinforces the importance of talent and creativity among other design professionals. However, in the exhibition, only the outcomes of the design process are displayed, not the struggles, setbacks and the breakthroughs in the design process, and consequently the narrative can appear thin unless you know the backstory.

Examining the spatial narrative through Greimas's scheme we could say the visitors to the exhibition became the subjects searching for design knowledge, creativity, immersive experiences and social connection. With the exception of Adam Nathaniel Furman, the designers were seldom mentioned. The brands were named. The brands were positioned as those moving the industry forwards, more powerful than the designers. Visitors were not invited to explore the brands in themselves, just marvel at their achievements and revel in their polished and appealing appearance.

The main obstacle in the spatial narrative of the exhibition as a whole was the cost of the tickets for those parts of the exhibition that was not free and which allowed individual visitors to move from 'my world' to 'their world'. The helpers were the ushers, security staff and hosts in the exhibitions and popups.

The King's Cross development area became a contextual narrative frame. The larger structures in Granary Square attracted attention through their size and colour. The narrative drama of struggle was 
displaced by the visual drama of the bold installations located against the 'raw' setting (the word raw was used in the exhibition publicity) of Granary Square. The visual drama was then experienced through the delight of aesthetic and bodily immersion. The 'raw' in Granary Square comprised the tall Victorian brickwork walls, the roofing ironwork and the cast iron gasometer and borrowed landscape of cranes and building sites to the west of the square. One of the most renowned UK designers, Thomas Heatherwick, had designed the new retail centre which was under construction to the west and becomes a cue, conjuring up notions of creativity and celebrity. On closer observation, other somewhat contradictory cues became clear, the area had been refurbished and was spectacularly clean and elegant. Argent, the developers, said themselves they wanted to create a space that was clean and safe. The quality of the space was matched by the high production values of the exhibits throughout the show. Indeed, the environment was very far from being raw, it was rather that polished and expensive products and structures were seen against clean and polished architectural heritage. It may be that the exhibition wanted to differentiate itself from trade shows and the Kings Cross setting certainly offered more drama than a neutral exhibition centre. However, it could be argued the sanitised heritage also weakened the narrative.

The word 'immersive' was used by designjunction to distinguish this exhibition from trade shows to suggest a deeper more transformational experience was on offer. To reinforce this, they selected Adam Nathaniel Furnham's Gateways for the centre of Granary Square and described him in the publicity as an artist. Gateways attracted attention through its shape, size, colour and location in front of the entrance to CSM inviting people going in and out of the entrance to walk through it.

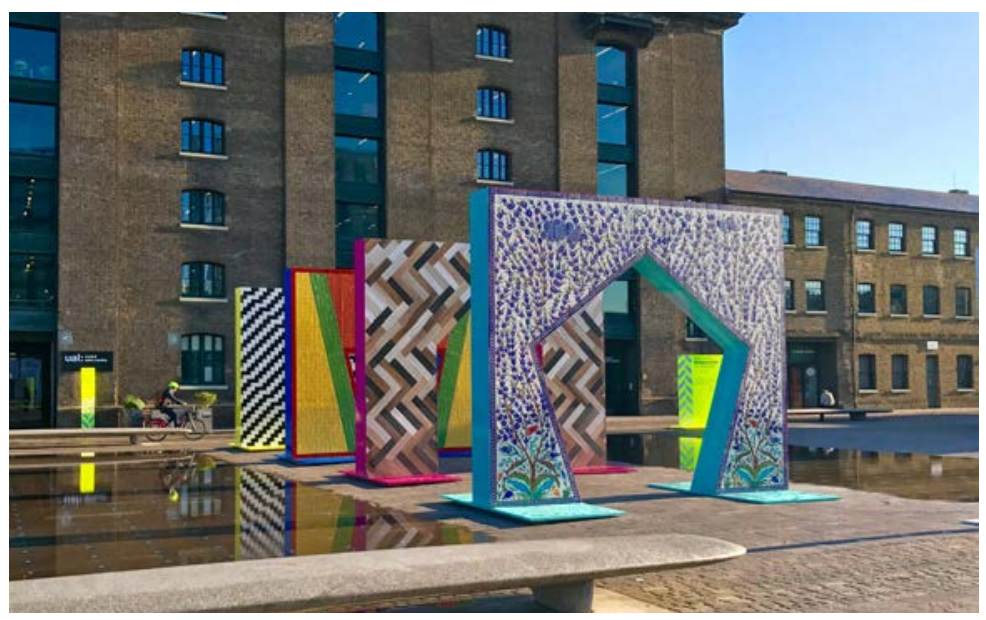

Figure 9

Gateways by Adam Nathaniel Furman, Granary Square 
Gateways comprised four gates, each inspired by a different design history. The Classic Gateway was covered in decorative hand-painted tiles which are traditionally used on mosques. The Timber Gate featured contemporary flooring tiles designed to look like wood or stone. The Retro Gate was covered in colourful square tiles arranged to create patterns that evoke the tiling used inside London Underground stations in the 1970s. The Metro Gate featured monochrome, rectangular, metro tiles, which have seen a resurgence in popularity in bars and cafes over recent years. It seemed the installation was an opportunity to show how tiles can be used on an architectural scale. It was billed as a story of the development of Turkish tiles but it appeared more an exploration of scale and material, an architectural experiment.

Indeed, there was a little account of historical events. Furman (personal communication, December 5, 2017) said the installation did have a clear narrative but it was not overtly expressed in the piece. There was some text on one wall but is was descriptive. He said he likes to use historical references which are in no way ironic or knowing, just hints. Greimas' axis of knowledge remained unopened.

In Greimas' scheme, Furman is the subject who desires the knowledge and achievement of using the tiles on a huge scale to evoke historical precedents and the power to enthral a wide audience. He said, "I have a personal interest in grandeur and monumentality, combined with a sensuality, swamps you with deliciousness" (Furman, personal communication, December 5, 2017). He explained Gateways was a direct reference to ancient entrance ways which often have large monumental surfaces and smaller entrances within. Furman is deeply involved in architectural heritage and the dramatic conflicts of destruction versus reuse and reinterpretation, but here ironically it could be argued Furman cut the tile loose from its history to be just another building material. As it turned out, he was accused by Sean Griffiths (2017), of blindly promoting Pomo (postmodernism) which started a furious debate online among the architectural community. Furman's Gateways, while intending to be an immersive delight, ignited tensions in the world of architecture. Gateways consequently produced another story in the press with vociferous opponents.

How did the spatial expression of the narrative work? The location and physicality of Gateways certainly invited attention. The pattern was visually appealing. The scale was clearly big enough to allow visitors to enter. In fact, the installation encouraged entry and movement through its arched and repeated form and unfolding sequence but there was no explicit story unfolded. 


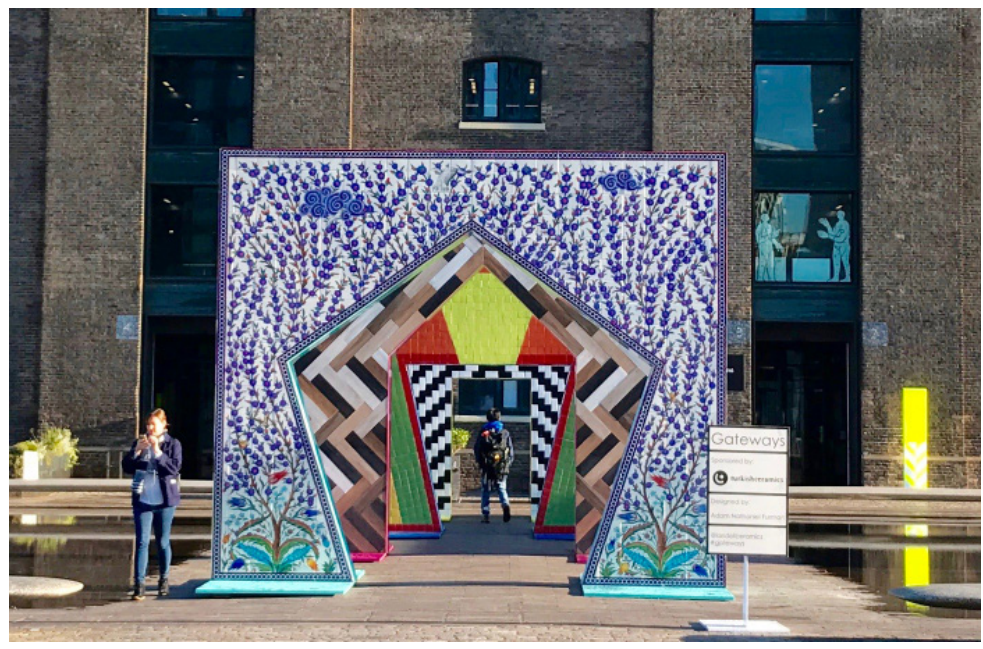

However, it is possible the architecture and interior design world would have been able to interpret the unconventional monumental use of tiles as a statement. Otherwise, Gateways provided an aesthetic experience which allowed anyone passing by to incorporate it into their own life narrative. Following Parsons' worlds 'my world' as a local resident or worker is temporally enriched by drifting into 'their world', the world of the designer and the design industry. For the design visitor, Gateways functioned as an icon of 'our world' and for the designjunction it worked in two ways: firstly, to elevate the status of the exhibition into 'their world', the art world; while, secondly, offering a delightful experience to passers-by in 'their world', that is the everyday world of, for example, a commuter walking through the square.

The Granary Square itself acts as a 'room' in the city bordered, as it is, by historic and modern buildings and a canal, and patrolled by security staff, albeit discreetly. People can enter from three different directions and the exhibits acted like islands which could be visited in any order. The exhibition did not draw citizens into a critical debate. It is, rather, subsumed into Argent's ongoing narrative, offered up as cues to an episode in a larger story of the regeneration of King's Cross. The whole could be described as a narrative environment expressing an implicit narrative of renewal through aesthetics and sensory immersion.

\section{Conclusion}

The analysis above has explored how narrative environments are different from media narratives because they are designed for em-
Figure 10 A view through Gateways showing the diminishing size of each arch 
bodied experience through space over time using scale, modulation, materiality, light, colour, text and the movement and behaviour of others to structure and communicate the story. It also examined how narrative environments in certain circumstances, among certain audiences, such as the passers-by in Granary Square, can get absorbed into the everyday, while for others, such as designers visiting designjunction, installations such as Gateways provide a tangible expression of the processes of design practice.

A key factor here is the cultural or narrative frame. The framing context was vital to the exhibitors analysed above, both of which attempted to show the value in forms of popular culture, as pop/ electronic music or mass-produced tiles, but also distinguish their design from mass culture. The irony is that in the case of Gateways, a commercial exhibition raised more critical discussion than the high cultural one at the V\&A. However, on a commercial level, it also reinforced the Argent brand story of the development of Granary Square by associating creativity, bodily immersion, aesthetics as beauty and renewal with innovation central to business and prosperity. Here there is a parallel with Their Mortal Remains. The V\&A exhibition served to perpetuate the band's brand narrative and consequently the existing power relations in the music industry, rather than offering insight into the industry and prompting critical debate. Although it aimed to show the V\&A as closely engaged with popular culture, the very fact it was shown in such a grand and auspicious building and institution served to validate the Pink Floyd as high culture. These case studies raise questions, on the one hand, about how well-known and grand museums can overcome their cultural and physical frame in order to more deeply critique, educate and inform and, on the other hand, how trade shows can be more insightful and informative.

In relation to entering literally and moving through different cultural frames, Parsons' extension of Greimas's semiotic square is also very useful in tracking when and how visitors might weave in and out of their own worlds, the exhibition world, and create a sense of a shared world and of learning. This is a spatio-political and psychodynamic modulation and provides designers of narrative environments with multiple concerns that can enable them to develop a more substantial design process than one that based mainly on spectacle or sensory stimulation. Adopting Parsons' scheme enables designers to engage with broad social and political issues and facilitates design practices' incorporation of Lefebvre's theories.

Returning to the case study analysis, Greimas' scheme proved useful in analysing the visitor, the narrative and the narrative environment. Firstly, Greimas' story dynamics reveal that the moving visitor 
becomes the subject seeking and desiring, empowered or disempowered by both the story and its spatial and material expression. It is interesting to note that the act of searching is where the visitors become engaged, otherwise they simply remain passive receivers in a didactic act. Secondly, Greimas' story dynamics reveal the importance of obstacles and opponents in story experiences. It is interesting that both exhibitions avoided dealing explicitly with dramatic conflict and instead engaged audiences through sensory stimulation, immersive audio-visual qualities and increasing scale in the V\&A and decreasing scale in the arches in Gateways. It is concluded that design teams need to play more imaginatively and experimentally with dramatic conflicts in order to fully develop a critical position and a compelling story, otherwise narrative environments can become a list of events or a sequence of objects that lack an engaging or purposeful developmental thread. The question is: what struggle underlies our narrative and how that can be embodied and expressed in material, spatial, visual or audio form?

\section{References}

Bruner, J. (1991). Self-making and world-making. Journal of Aesthetic Education, 25(1), 67-78.

Greimas, A. J. (1983). Structural semantics: An attempt at a method. Lincoln: University of Nebraska Press.

Greimas, A. J. (1987). On meaning. Minneapolis: University of Minnesota Press.

Griffiths, S. (2017, October 30). Now is not the time to be indulging in postmodern revivalism. Retrieved from https://www. dezeen.com/2017/10/30/sean-griffiths-fat-postmodernrevivalism-dangerous-times-opinion/

Hawhee, D. (2002). Agonism and arete. Philosophy and Rhetoric, 35(3), 185-207.

Kossmann, H., Mulder, S., \& Oudsten, F. (2012). Narrative space: On the art of exhibiting. Rotterdam: 010 Publishers.

Latour, B. (2005). Reassembling the social: An introduction to actornetwork-theory. Oxford: Oxford University Press.

Latour, B. (2014). Agency at the time of the Anthropocene. New Literary History, 45(1), 1-18.

Lefebvre, H. (1991). The construction of space. Oxford:Wiley-Blackwell Publishing. 
McKee, R. (1999). Story: substance, structure, style and the principles of screenwriting. London: Methuen.

Merleau-Ponty, M. (2005). Phenomenology of perception. (C. Smith, Trans.). London: Routledge.

Parsons, A. (2017). Actant and actantiality (Unpublished lecture). Central Saint Martins, UAL, London.

Perec, G. (2008). Species of spaces. London: Penguin.

Potteiger, M., \& Purington, J. (1998). Landscape narratives: Design practices for telling stories. New York: Wiley.

Psarra, S. (2009). Architecture and narrative: The formation of space and cultural meaning. London: Routledge.

Ryan, M. (2016). Narrating space/spatializing narrative: Where narrative theory and geography meet. Columbus: The Ohio State University Press.

Wegner, P. E. (2010). Greimas avec lacan; or, from the symbolic to the real in dialectical criticism. Criticism, 51(2), 211-245. 